\title{
AGING AND SOCIAL ENGAGEMENT: CULTURAL INFLUENCES
}

\author{
Sajjad Hussain \\ $\mathrm{PhD}$, Scholar, International Islamic University, Islamabad, Pakistan \\ ddoswmn1234@gmail.com
}

Dr. Saif ur Rehman Saif Abbassi

Professor of Sociology, International Islamic University, Islamabad, Pakistan Address: saif_abbasi2002@yahoo.com

\begin{abstract}
The study aimed to investigate the changing culture of social engagement toward aged persons along with stereotypes that aged person be constrained in their contacts and engagement. Despite the fact that the society of Pakistan is rooted on the culture that dignifies the lives of aged person and place them on the high position of virtue but current reaction of the society is hostile regarding their engagement in terms of local community connections, religious connections and work connections by stereotypes that elderly are supposed to perform limited role. The study aimed to assess the level of social engagement, opportunities available and encouragement from different stake holder of society for the aged persons. In order to explore, the study targeted retired pensioners from government department across the south Punjab region by focusing all cadres of pensioner's i.e. Class-IV, Clerical Cadre and Gazatted. The study selected 400 retired pensioners (i.e. 302 male 98 females) from districts Multan, Khenewal, Bahawlpur, Rahim Yar Khan, Dera Ghazi Khan and Muzaffargarh of South Punjab, through stratified random sampling technique. The study used proportionate sampling technique in order to select true representatives of the population from each selected district. The study used self-constructed Social Engagement Scale for data collection through survey method and face-to-face interview schedule. The study concluded that aged persons deserve dignified life in the society. For this state should device the policies and their implementations as well along with society proactive role for those who had served their potential and still can add for the betterment of society as well.
\end{abstract}

Keywords: Population ageing, Social engagement, Cultural influences

\section{INTRODUCTION}

Social engagement refers to making social and emotional connections with people and the community, is related to social integration, social support, and social interaction, all of which influence health and psychological well-being (Baltes, 1996; Mendes de Leon, Glass, \& Berkman, 2003; Tomaka, Thompson, \& Palacios, 2006). Although making connections with people and the community is a lifelong process, the quantity and quality of social ties change over the life course especially with advancing age and the onset of physical and mental limitations, as well as when the social context changes (Antonucci \& Akiyama, 1995; Carstensen \& Charles, 1998; Eng, Rimm, Fitzmaurice, \& Kawachi, 2002; Lansford, Sherman, \& Antonucci, 1998; Shaw, Krause, Liang, \& Bennett, 2007). It has been established that the society reaction toward aged persons is becoming hostile and they are being restrained to have their contacts and participation which pose many negative effects and the burden toward families and society by not utilizing the skills and experience. Moreover, the persons of society in form of trained potential i.e. retired pensioners facing same sort of problems by the specific mindset of society toward retired pensioners.

Cultural beliefs shape social norms and values surrounding the aging process and the role of aged persons (Nelson, 2004) and these beliefs about aged persons are not static. They vary from society to society. However, there has come a shift in the societies that aged persons are expected to be limited socially engaged (Palmore, 1999). It has raised the questions on the dignity and the potential they have-based on their life experiences. Hence, they are being pushed toward social exclusion which has numerous negative effects on the aged persons. This changing culture based on stereotypes need to be addressed to restore the dignity of aged person in societies. In sum, the mandates at a political level encompass the recognition of social engagement, participation and full inclusion in all aspects of life as fundamental human rights. Thus, fostering participation entails 
guaranteeing justice of opportunities and basic social security within a democratic organization of society and economy, as well as the creation of age-friendly social and physical environments, while recognizing the right of citizens to share their living space throughout the whole course of life.

The situation of Pakistan's society is no more different with reference to social engagement and questions on the dignity and independence have been raised to continue their connections in the age 60 and above. The retired pensioners being the trained potential are also facing the issue of constrained participation due to their age with the stigma of "retired ". It means that he is no more required to give his input for the society and his dignity has been questioned due to retirement. They have been restrained to perform limited role and their participation. Despite the fact that society has always stood for high value, respect and dignity for aged persons but the changing culture and specific approach with respect to aged persons has forced the aged person their participation and frequency of participation has been questioned which is totally aging the norms and values of the society based on religion (Islam) which abide by their believers to ensure the dignity of their aged persons (Itrat et al. 2007).

This changing culture is the result of different factors like conversion of extended family system and joint to nuclear family, urbanization and migration (Sabzwari \& Azhar, 2011; Ashiq \& Asad, 2017). The Pakistani society has been remained rich in its civic repute (Jalal \& Younis, 2014). Aging and elderly in. The people have supported and encouraged to be engaged with the society but the situation as whole by society is becoming hostile regarding the social participation and maintaining the contacts specifically to the aged persons. The aged person are stigmatized that they should have limited contacts and limited participation as it wrongly believed that it lessens the pressure on the families and the society. This issue needed to explored and awareness to restore the dignity of the elder persons by giving them full chance of participation in different social sphere of life along with the encouragement to participate in the productive actives like working for community welfare, religious activities for the betterment of the society and for their betterment as well and to achieve this society's member mindset be changed by advocating the age friendly culture based on the concept of dignity.

\section{REVIEW OF LITERATURE}

Recent researches have consistently demonstrated the importance of lifestyle factors, such as active involvement in social activities and social networks, in a variety of health outcomes, including physical illness, mental health and mortality (Everard, Lach, Fisher, \& Baum 2000; Glass, De Leon, Bassuk, \& Berkman, L. F.2006; Sampson, Bulpitt, \& Fletcher, 2009). Tsai and colleagues (2009) examined the prevalence and associated risk factors of poor social engagement in residents aged $\geq 65$ years living in a veteran's home. They found that poor social engagement was common in this sample, and that the independent risk factors for poor social engagement included depression, illiteracy, the presence of unsettled relationships, and cognitive impairment. However, it has not been focused in the researches that the changing culture and as a whole reaction of the societies that are going to restrict their participation and contacts in the society.

Two theories that explain age-related changes in social relationships and adaptation provide a conceptual framework to understand the patterns of social engagement in later life. Socioemotional selectivity theory suggests that because a perception of limited time remaining in life becomes heightened with aging, individuals more selectively invest in relationships that are emotionally fulfilling. Thus, priorities in social relations shift and older adults selectively invest in important social ties while discarding those that are more peripheral (Carstensen, Fung, \& Charles, 2003; Kahn \& Antonucci, 1981; Lang \& Carstensen, 1994). In addition, the selective optimization with compensation framework explains that older adults adapt to changes in their health and social network by selectively investing and compensating their behavior to maximize their capacity (Baltes \& Baltes, 1990). In this theory, for example, older adults with increasing physical and cognitive impairments may narrowly focus on the relationships they can manage.

The factors that affect social engagement in the elderly are various, including physical function, mental function, and socioeconomic issues. Depression-related social withdrawal, loss of energy and poor attention can be barriers to social interaction. Of note, depression is a treatable disorder. In fact, the relation between low social engagement and depression is reciprocal. It has also been shown that being socially isolated and inactive is associated with an increased risk of onset of 
major depressive disorder. Social disengagement has been reported to be associated with cognitive impairment or dementia in the elderly. The activity theory emerged from the observation of the positive relationship between greater levels of social involvement and satisfaction with life among the elderly. According to this theory, a person is most likely to succeed in old age if they continue to be active and take on productive roles in society, replacing those that have been lost. These productive roles include community-based social activities, such as paid work, volunteering, and participation in social or religious groups

The continuity theory postulated that, although individuals adapt to the aging process by adjusting the duration, mode, and distribution of activities, they tend to participate in similar activities and to continue the lifestyles adopted in adult life and middle age. Therefore, social participation patterns remain relatively stable during one's life course. Therefore, dynamism in the patterns and levels of social engagement is accepted and includes as determinants personal motivations and preferences for activities and institutional factors.

Sociological theories take into account various dimensions of ageing: the biological age, psychic and social age, whereby ageing is to be viewed as an important dimension of social structures. The social significance of ageing, exploring how age is socially constructed, what social expectations and roles are attached to ageing and what forms of ageism elderly people need to face. However, it has been less studied to dignify the aged person having experience and trained potential for serving the society and encouragement by the society regarding their participation in welfare activities The theoretical changes, accompanied by the dissemination of empirical data, have driven conceptual transitions in the field of Gerontology, challenging scholars and practitioners to deal with aging as a complex and heterogeneous process. In this context, engagement or social participation has become an important object of study with reference to its positive outcomes along with the restricted participation of elderly people due to changing culture

\section{METHODOLOGY}

To measure frequency of opportunities, encouragement by the society in terms of Local community connections, religious connections and work connections toward the retired pensioners the study selected 400 retired pensioners from districts Multan, Khenewal, Bahawlpur, Rahim Yar Khan, Dera Ghazi Khan and Muzaffargarh of South Punjab including male (302) and females (98), through stratified random sampling technique. The study used proportionate sampling technique in order to select true representatives of the population from each selected districts. As the study target population were retired pensioners from government department across the south Punjab region it was given representation to all cadres of pensioner's i.e., Class-IV, Clerical Cadre and Gazatted according to their strength available in the sampling frame. The study used self-constructed Social Engagement Scale for data collection through survey method and face-to-face interview schedule.

Table 1

Selection of sample through proportionate sampling technique

\begin{tabular}{lllll}
\hline Sr\# & Division & Districts & No. Pensioner & Proportion \\
\hline 1 & Multan & Multan & 17900 & 84.43 \\
2 & & Khanewal & 9580 & 45.19 \\
3 & D.G. Khan & D.G. khan & 11475 & 54.13 \\
4 & & M. Garh & 13160 & 62.1 \\
5 & Bahawalpur & Bahawalpur & 16960 & 80.0 \\
6 & & Rahim Yar Khan & 15720 & 74.15 \\
& & Total population & $\mathbf{8 4 7 9 5}$ & \\
& & Sample size & $\mathbf{4 0 0}$ & Total proportion 400 \\
\hline
\end{tabular}

Source: As per data obtained from Accountant General Punjab (AGP), 2019. 


\section{FINDINGS OF THE STUDY}

Table. 1

Percentage distribution of respondents regarding their social engagement in terms of local community connections and religious connections

\begin{tabular}{|c|c|c|c|c|c|c|c|c|c|}
\hline \multirow{2}{*}{$\begin{array}{l}\text { Local Community } \\
\text { Connections }\end{array}$} & \multicolumn{2}{|c|}{ Never } & \multicolumn{2}{|c|}{ Sometimes } & \multicolumn{2}{|c|}{ Frequently } & \multicolumn{2}{|c|}{ Always } & \multirow{2}{*}{$\begin{array}{l}\text { Total with } \\
\text { Percentage }\end{array}$} \\
\hline & $f$ & $\%$ & $f$ & $\%$ & $f$ & $\%$ & $f$ & $\%$ & \\
\hline $\begin{array}{l}\text { Involvement in welfare } \\
\text { activities }\end{array}$ & 136 & 34.0 & 83 & 20.8 & 52 & 13.0 & 129 & 32.3 & $400(100 \%)$ \\
\hline $\begin{array}{l}\text { Value regarding services } \\
\text { rendered }\end{array}$ & 101 & 25.3 & 164 & 41.0 & 83 & 20.8 & 52 & 13.0 & $400(100 \%)$ \\
\hline $\begin{array}{l}\text { Working for Community } \\
\text { Welfare }\end{array}$ & 52 & 13.0 & 168 & 42.0 & 87 & 21.8 & 52 & 13.0 & $400(100 \%)$ \\
\hline $\begin{array}{l}\text { Services extended by } \\
\text { organization }\end{array}$ & 109 & 27.3 & 156 & 39.0 & 83 & 20.8 & 52 & 13.0 & $400(100 \%)$ \\
\hline $\begin{array}{l}\text { Invitation for welfare } \\
\text { activities }\end{array}$ & 109 & 27.3 & 156 & 39.0 & 83 & 20.8 & 52 & 13.0 & $400(100 \%)$ \\
\hline $\begin{array}{l}\text { Family encouragement to } \\
\text { participate in welfare } \\
\text { activities }\end{array}$ & 101 & 25.3 & 153 & 38.3 & 86 & 21.5 & 60 & 15.0 & $400(100 \%)$ \\
\hline $\begin{array}{l}\text { Happiness of family in } \\
\text { social engagement after } \\
\text { retirement }\end{array}$ & 109 & 27.3 & 139 & 34.8 & 100 & 25.0 & 52 & 13.0 & $400(100 \%)$ \\
\hline $\begin{array}{l}\text { Involvement in charity } \\
\text { related activities }\end{array}$ & 39 & 9.8 & 117 & 29.3 & 107 & 26.8 & 137 & 34.3 & $400(100 \%)$ \\
\hline $\begin{array}{l}\text { Involvement in resolving } \\
\text { the conflict of the area. }\end{array}$ & 125 & 31.3 & 140 & 35.0 & 83 & 20.8 & 52 & 13.0 & $400(100 \%)$ \\
\hline $\begin{array}{l}\text { Participation in politics } \\
\text { after retirement }\end{array}$ & 129 & 32.3 & 136 & 34.0 & 83 & 20.8 & 52 & 13.0 & $400(100 \%)$ \\
\hline $\begin{array}{l}\text { Going for Mosque/Church } \\
\text { etc. }\end{array}$ & 86 & 21.5 & 105 & 26.3 & 28 & 7.0 & 181 & 45.3 & $400(100 \%)$ \\
\hline $\begin{array}{l}\text { Involvement in resolving } \\
\text { Mosque/Church issues }\end{array}$ & 101 & 25.3 & 196 & 49.0 & 10 & 2.5 & 93 & 23.3 & $400(100 \%)$ \\
\hline $\begin{array}{l}\text { Involvement in Zakat/ } \\
\text { Sadqat Committees }\end{array}$ & 238 & 59.5 & 50 & 12.5 & 20 & 5.0 & 92 & 23.0 & $400(100 \%)$ \\
\hline
\end{tabular}

The table 1 showed that percentage of the respondents who never and always involved in welfare activities is slightly similar (34\% and $32.3 \%$ respectively) and these percentages are high comparing with the categories of sometimes $(20.8 \%)$ and frequent $(13 \%)$ involvement in welfare activities.

The table also revealed about the value regarding the services rendered by the aged, retired respondents. As the data showed, (41\%) of the respondents reported that it happened sometimes that their services are acknowledged by the colleagues or the organization while lower than the quarter of the total respondents $(20.8 \%)$ said that their colleagues or the organization they have served in frequently value their services rendered. Interestingly, (13\%) of the respondents said that their services have always been valued. On the contrary, the quarter of the total respondents $(25.3 \%)$ reported that their services to their organizations have never been valued.

It was found that less than half $(42 \%)$ of the total respondents have sometimes been working for community welfare and only $(21.8 \%)$ of the respondents reported to work frequently for the welfare of their community. On the other hand, equivalent percentage of the respondents reported that they have always and never (13\% each) engaged in community welfare. 
The table also showed that (39\%) and (20.8\%) of the respondents reported that their services are extended by their organizations sometimes and frequently, respectively. However, $(27.3 \%)$ of the respondents said that their services have never been extended. On the other hand, it was found that services of $(13 \%)$ of the respondents have always been extended by their organizations.

In order to avail the opportunity of available skills in terms of aged person, it is quite possible that people may ask them to enlighten or help other through their enriched experience. Therefore, the research also measured such opportunities and found that $(13 \%)$ of the respondents has always received invitation to offer welfare activities to other. Contrarily, $(27.3 \%)$ of the respondents reported that they never received such invitation. Further, it was also found that (39\%) of the respondents were sometimes contacted for such services and $(20.8 \%)$ were frequently contacted to participate in welfare activities.

However, considering the age of the person, it is also possible that families of such aged persons may restrict them to participate in any of the activities and prefer leisure for him/her. Thus, the researcher also asked the respondents about the encouragement of the families towards the aged persons for participation in welfare activities. It was found that (15\%) families of the respondents always encouraged them to take a part in welfare activities. However, $(25.3 \%)$ of the families never encouraged their aged family member to participate in such activities. Furthermore, it was also found that the percentage of the families who sometimes encouraged their aged person to participate in welfare activities is higher than the other categories as (38.3\%) of the families of aged person sometimes encouraged them to take part in such activities. However, $(21.5 \%)$ of the families frequently encouraged their old, aged persons participating in welfare activities.

However, it is important to measure whether such encouragement is posed? Thus, the researcher also asked about the happiness of family while the aged person participate in welfare activities after retirement. It was found that $(27.3 \%)$ of the families never became happy for such participation, whereas $(13 \%)$ of the families were always found happy on such activities of the aged persons. Further, $(34.8 \%)$ and $(25 \%)$ of the respondents reported that their family sometimes and frequently, respectively, became happy on such their welfare activities.

The researcher further probed about the type of activities of the aged persons and found that only $(9.8 \%)$ of the respondents never participated in charity related activities. However, $(34.3 \%)$ of the respondents reported that they were always ahead in participating charity related welfare activities. It was also found that $(29.3 \%)$ and $(26.8 \%)$ of the respondents sometimes and frequently, respectively, participated in such activities.

Nevertheless, when it comes to conflict resolution, the percentage of the never participating in such welfare activities is higher i.e. (31.3\%) than the always participating which is (13\%). However, (35\%) of the respondents reported that they sometimes got involved in conflict resolution, whereas $(20.89 \%)$ of the respondents said that they frequently indulged in such resolution.

Lastly, the research measures the active political participation which revealed that $(32.3 \%)$ of the respondents never participated in politics after retirement, whereas $(13 \%)$ of the respondents said that they always participated in politics. Further, it was also found that (34\%) and $(20.8 \%)$ of the respondents sometimes and frequently, respectively, participated in politics after retirement.

Measurement of religious connections (see Table 1) revealed that tendency among pensioners to be the part of religious practices but participation in religious affairs was not found significantly encouraging. There was found that the pensioners preferred to go for mosque/ church etc for the obligations of the religious practices. As the majority of the respondents of the study were male; they are supposed to go for prayer in the mosque as it is norm prevailing in the society. As prayer/ Salat for the Muslims is obligation to pray in the mosque in specific times. The holy book of Muslims i.e Quran has abided the Ummah to pray the Prayer/ Salat and it has been mentioned seven hundred times in the book. However, the volunteer engagement in resolving mosque/ Church issues was found limited. The arrangement of Imam at mosque and payment to him can be the part of mosque related issues. Moreover, the mosque/church related financial burden are not going to be bear by the state. These financial arrangements for the functioning is supposed to be arranged by those who come to pray. Such engagement of the respondents found that the majority of the respondents were going to be involved in mosque/church related issues on occasional/ sometimes basis.

Table 1 also consisted of frequencies and percentage distribution of one of the subscales of social engagement i.e., religious connections. It was found the tendency among respondents to be the 
part of religious practices. The respondents preferred to go to mosque/ church etc. for religious obligations. As majority of the respondents of the study were male; they are supposed to go for prayer in the mosque as it is norm prevailing in the society. It is also a matter of deep consideration that senior citizens are more focused to pray the prayer in the mosque. The holy book of Muslims i.e., Quran has focused for the Ummah to pray the Salat/ Prayer and it has been mentioned seven hundred times in the book.

Same practice has been found in the research as $(45.3 \%)$ respondents always were going to mosques for Salat/Prayer. It was also revealed that significant respondents $(26.3 \%)$ were sometimes going to mosque for the. The reason for visiting the mosque sometimes basis can be linked with different factors. These factors can be health of the respondents, availability of the time to go to mosque, distance of mosque/ church, and engagement preferences to pray in the mosque/church as well.

It was also found in the research that $(21.5 \%)$ respondents had never visited mosque after their retirement while $(7.0 \%)$ were frequently visiting mosque. Hence, majority of the respondents were going to mosque/ church for the prayer either always or sometimes.

The respondents who were going to mosque were also asked about their volunteer engagement in resolving mosque/ Church issues. The mosque/ church related issues can be the arrangement of different religious events at mosques, the arrangement of Imam at mosque and paying him. Moreover, the mosque/church related financial burden are not bearded by the state. These financial arrangements for the functioning is supposed to be arranged by those who come to pray. Such engagement of the respondents was investigated. It was found that majority of the respondents were involved in mosque/church related issues on occasional/ sometimes basis. The categorical percentage of such respondents were $(49.0 \%)$.

The reason for less involvement in mosque/church related issues was financial stability. As majority of the respondents of the research were working on lower grades and were drawing a pension in which they were not able to contribute for the payments of bills of the mosque/church etc. Hence the situation has not been found encouraging.

Retired pensioners who were the respondents of the study, despite having the professional experience were not being engaged in local zakat/ sadqat committees for helping the marginalized and vulnerable segment s of the society. Majority (59.5\%) of the respondents had never been engaged in Zakat/ Sadqat committees. The experience of this trained potential was not even used for the welfare of the marginalized population of their area. It was reported by the respondents that the persons having political contacts were engaged or encouraged their participation. So, it was an opportunity of engagement captured by the resourceful persons. In this regard government has not framed any policy to involve the trained potential for the welfare activates.

Retired pensioners, despite having the professional experience were not being engaged in local zakat/ sadqat committees for helping the marginalized and vulnerable segment $\mathrm{s}$ of the society. They were ignored and they had believed the persons involved in politics are preferred for the nomination of committees helping the vulnerable segments of society (See Table. 1). Table.2

Percentage Distribution of respondents by their Work Connections

\begin{tabular}{|c|c|c|c|c|c|c|c|c|c|}
\hline \multirow{2}{*}{ Work Connections } & \multicolumn{2}{|c|}{ Never } & \multicolumn{2}{|c|}{ Sometimes } & \multicolumn{2}{|c|}{ Frequently } & \multicolumn{2}{|c|}{ Always } & \multirow{2}{*}{$\begin{array}{l}\text { Total with } \\
\text { Percentage }\end{array}$} \\
\hline & $f$ & $\%$ & $f$ & $\%$ & $f$ & $\%$ & $f$ & $\%$ & \\
\hline Visit to ex department & 119 & 29.8 & 246 & 61.5 & 13 & 3.3 & 22 & 5.5 & $400(100 \%)$ \\
\hline $\begin{array}{l}\text { Ex-colleagues invite } \\
\text { for guidance }\end{array}$ & 204 & 51.0 & 138 & 34.5 & 33 & 8.3 & 25 & 6.3 & $400(100 \%)$ \\
\hline $\begin{array}{lr}\text { Privileged due to } \\
\text { experience } \\
\text { colleagues }\end{array}$ & 269 & 67.3 & 75 & 18.8 & 35 & 8.8 & 21 & 5.3 & $400(100 \%)$ \\
\hline $\begin{array}{l}\text { Arrangement of paid } \\
\text { work by ex- } \\
\text { colleagues }\end{array}$ & 374 & 93.5 & 22 & 5.5 & 4 & 1.0 & - & - & $400(100 \%)$ \\
\hline $\begin{array}{l}\begin{array}{l}\text { Honorary } \\
\text { arranged } \\
\text { colleagues }\end{array} \\
\text { by }\end{array}$ & 358 & 89.5 & 23 & 5.8 & - & - & 19 & 4.8 & $400(100 \%)$ \\
\hline
\end{tabular}




\begin{tabular}{lrlllllllll}
\hline Initiative by & 373 & 93.3 & 6 & 1.5 & 6 & 1.5 & 15 & 3.8 & $400(100 \%)$ \\
government to & & & & & & & & & \\
maintain relationship & & & & & & & & & \\
with ex-department & & & & & & & & & \\
\hline
\end{tabular}

Table. 2 consisted of frequencies and percentage distribution of the measures regarding work connections. As work connections are source to develop social capital. Social capital can facilitate in every sector of life in all ages. Aged persons need badly in the latter adult hood. As they have to secure for better health and social protection. It is important to discuss that these retired pensioners had a lot of experience, and they are trained potential to help those who are inducted in any department. Same was probed in this research for critical analysis how this capital is going to help them out and how they are being used to facilitate their ex- department colleagues. But the retired pensioners who had served their best potential are not being treated from the core of heart by their excolleagues. They are treated as a burden, and they are not dignified even for their experience and age in the department in which they had served many years. The concept of bridge employment is gaining popularity in the western countries and even in this country the retired pensioners are not encouraged for volunteer services (See table.2). The percentages reflected in the study presents the better picture to understand the issue of lack of social engagement by the hostile culture for the aged person even having the experience.

Visiting ex-department shows how the retired person is going to maintain his capital with the department and how he had earned importance for the department. It was reported by majority $(61.5 \%)$ of the respondents that they visited ex -department sometimes. It shows they are less connected with the ex-department because they are less valued by the department, or they had not earned a good repute during their service. A significant percentage $(29.8 \%)$ of the respondents reported that they had never visited their ex-department after their retirement.

Utilizing the experience of those persons who are professionally sound and had a lot of experience can resolve the issues faced by the juniors serving in the department. It was found that respondent was not significantly asked to guide the juniors in the department in which they had served. It was reported by half $(51.0 \%)$ of the respondents that they had never been requested for guidance by the ex-junior colleagues while $(34.5 \%)$ respondents reported that they had been requested sometimes for guidance.

It is of great value in the societies if a person is privileged due to his professional experience which he had earned in his life. But in this research, it has been found that retired pensioners did not enjoy that privilege. It was reported by majority $(67.3 \%)$ of the respondents that they had not been privileged due to their experience by their ex-colleagues while a nominal percentage $(18.8 \%)$ of the respondents reported that they had been privileged due to their experience by the ex-department sometimes. Interestingly, it was also reported by $(5.3 \%)$ that they had always been privileged due to their experience.

Due to economic instability in Pakistan, the pension provided to those employees especially retired in the non-gazette posts is not sufficient to meet their needs. And this problem puts a huge mental pressure when they had to arrange the marriages of their children especially daughters. Arrangement of daughter's marriages is being considered a huge value by those belonging to the culture of South Punjab. As provided pension by the government is not sufficient to meet the needs of the respondents, so they needed to do another job to address the reasonability they had to fulfil. It was probed in the research that the respondents were facilitated in hunting of paid job by their excolleagues. It was reported by majority (93.5\%) of the respondents that paid work had never been arranged by their ex-colleagues and department as well.

Social engagement has so many positive effects on the lives of those who had served their potential to facilitate public and their family. The retired pensioners due to their broad experience can be engaged in honorary works by giving them a specific place and honorary title to work for the betterment of the society. Same was probed in this research and it was reported by majority $(89.5 \%)$ of the respondents that they had never been engaged in honorary work by their ex-colleagues and department.

In terms of initiatives taken by the government for betterment of retired pensioners, majority of the respondents were not being facilitated by government except providing pension which was not 
going to meet their economic needs and were not being socially protected especially the retired pensioners from non-gazette posts. So, it was needed to address their issues by the government by devising the policies which can make their lives to boost their confidence to live a better life. Same was probed, it was reported by majority (93.3\%) of the respondents that government had never taken initiatives for them to facilitate them to resolve their problems. As they have served their whole life for the country and society so, just providing pension is not sufficient to address all the issues faced by the retired pensioners.

\section{DISCUSSION}

The purpose of the study was to highlight the issue of hostile reaction by the society as whole toward aged persons regarding their engagement in the society and even the retired pensioners which are the trained potential of the society have no exception. They are enriched with the experience and their experience can be utilized for the betterment of society by engaging them in productive activities. Instead of this they are facing numerous problems due to changing culture of the society and their participation and contacts are expected to be limited by the younger generations. The retired pensioners even have to live with the stigma of "retire" that culturally expressed that person abilities i.e., physical and mental are not trustworthy for any activity. Although all the retired pensioners are not living with the same physical and mental capabilities. This situation is hurting as whole especially in the Islamic Society in which aged persons are respected due to their age.

\section{CONCLUSION}

Aged persons belonging to any sphere of life deserve highest respect and position in the society. It is needed to be addressed at state level to introduce the policies to dignify those people who had served their best potential not only for their families by feeding them but for the state as whole. The changing culture which is adversely affecting the aged person needed to rectify with the norms of dignified aged person by launching as whole awareness campaign by using all forums.

\section{ACKNOWLEDGEMENT}

It is hereby acknowledged that above titled research paper submitted in this journal has been produced from PHD research of principal author. Further this research paper has been not submitted to any other journal, nor published and not in review.

\section{REFERENCES}

Baltes, M. M. (1996). The many faces of dependency in old age. Cambridge University Press.

Mendes de Leon, C. F., Glass, T. A., \& Berkman, L. F. (2003). Social engagement and disability in a community population of older adults: The New Haven EPESE. American journal of epidemiology, 157(7), 633-642.

Tomaka, J., Thompson, S., \& Palacios, R. (2006). The relation of social isolation, loneliness, and social support to disease outcomes among the elderly. Journal of aging and health, 18(3), 359-384.

Shaw, B. A., Krause, N., Liang, J., \& Bennett, J. (2007). Tracking changes in social relations throughout late life. The Journals of Gerontology Series B: Psychological Sciences and Social Sciences, 62(2), S90-S99.

Lansford, J. E., Sherman, A. M., \& Antonucci, T. C. (1998). Satisfaction with social networks: An examination of socioemotional selectivity theory across cohorts. Psychology and aging, 13(4), 544.

Eng, P. M., Rimm, E. B., Fitzmaurice, G., \& Kawachi, I. (2002). Social ties and change in social ties in relation to subsequent total and cause-specific mortality and coronary heart disease incidence in men. American journal of epidemiology, 155(8), 700-709.

Carstensen, L. L., \& Charles, S. T. (1998). Emotion in the second half of life. Current Directions in Psychological Science, 7(5), 144-149.

Antonucci, T. C., \& Akiyama, H. (1995). Convoys of social relations: Family and friendships within a life span context.

Kahn, R. L., \& Antonucci, T. C. (1981). Convoys of social support: A life-course approach. Aging: Social change, 383-405. 
Lang, F. R., \& Carstensen, L. L. (1994). Close emotional relationships in late life: Further support for proactive aging in the social domain. Psychology and aging, 9(2), 315.

Carstensen, L. L., Fung, H. H., \& Charles, S. T. (2003). Socioemotional selectivity theory and the regulation of emotion in the second half of life. Motivation and emotion, 27(2), 103-123.

Baltes, P. B., \& Baltes, M. M. (1990). Psychological perspectives on successful aging: The model of selective optimization with compensation.

Nelson, T. D. (Ed.). (2004). Ageism: Stereotyping and prejudice against older persons. MIT press.

Palmore, E. (1999). Ageism: Negative and positive. Springer Publishing Company.

Sabzwari, S. R., \& Azhar, G. (2011). Ageing in Pakistan-a new challenge. Ageing International, 36(4), 423-427.

Jalal, S., \& Younis, M. Z. (2014). Aging and elderly in Pakistan. Ageing International, 39(1), 4-12.

Ashiq, U., \& Asad, A. Z. (2017). The rising old age problem in Pakistan. Journal of the Research Society of Pakistan-Vol, 54(2).

Everard, K. M., Lach, H. W., Fisher, E. B., \& Baum, M. C. (2000). Relationship of activity and social support to the functional health of older adults. The Journals of Gerontology Series B: Psychological Sciences and Social Sciences, 55(4), S208-S212.

Glass, T. A., De Leon, C. F. M., Bassuk, S. S., \& Berkman, L. F. (2006). Social engagement and depressive symptoms in late life: longitudinal findings. Journal of aging and health, 18(4), 604-628.

Sampson, E. L., Bulpitt, C. J., \& Fletcher, A. E. (2009). Survival of community-dwelling older people: the effect of cognitive impairment and social engagement. Journal of the American Geriatrics Society, 57(6), 985-991.

Tsai, C. F., Ouyang, W. C., Chen, L. K., Lan, C. F., Hwang, S. J., Yang, C. H., \& Su, T. P. (2009). Depression is the strongest independent risk factor for poor social engagement among Chinese elderly veteran assisted-living residents. Journal of the Chinese Medical Association, 72(9), 478-483. 